\title{
O HIPNOTISMO E A LEGISLAÇÃO PENAL BRASILEIRA
}

\author{
Nelson Ferreira da Luz \\ Professor da Faculdade de Direito da Universi- \\ dade do Paraná.
}

Dispunha a Consolidação das Leis da República, no seu título $3 .^{\circ}$, artigo $27, \S 4 .^{\circ}$ :

"Não são criminosos: Os que se acharem em estado de completa perturbação dos sentidos e inteligência no ato de cometer o crime".

Essa disposição, que veio substituir a primitiva: “os que se acharem em estado de completa privação dos sentidos e inteligência no ato de cometer o crime", data de 27 de Dezembro de 1923 , quando o Decreto 4.780 , no seu artigo 38 , substituiu a palavra privação por perturbação.

Muito embora o Dr. Batista Pereira, autor do Código, mostrasse, num parecer dado (sôbre-projeto do Código Penal, em 28 de junho de 1897) ter havido um êrro, uma vez que o original do artigo em questão fazia referência a perturbação, êste continuou a ser interpretado com a palavra privação, suscitante, na prática forense e entre os estudiosos da matéria penal, as mais acerbas críticas e desastrosas consequências.

Privação de sentidos e inteligência é, no entender dos que criticaram a letra da lei, entre os quais o eminente mestre Dr. Souza Lima, um estado de morte aparente, de letargia ou de coma, em que pessôa alguma poderá praticar um crime.

Caso idêntico de êrro deu-se ainda com relação à frase "sentidos e inteligência". 0 legislador, num artigo que 
escreveu para a Revista de Jurisprudência (vol. 2. ${ }^{\circ}$ pgs. 374-376) afirmou haver usado a conjunção ou, em vez de e. Ficava assim sendo necessário, portanto, de acôrdo com a letra de lei, uma vez que persistia o senão, que a completa perturbação da inteligência coexistisse com a completa perturbação dos sentidos, no ato do cometimento do delito, para que o criminoso pudesse invocar em seu favor a dirimente.

A expressão completa perturbação, técnicamente considerada, foi alvo de interpretações as mais variadas. Diz o Dr. Souza Lima: "os casos de loucura moral, de loucura impulsiva, que se processam sem prejuizo da integridade do $\mathrm{Eu}$ consciente e raciocinante, escapam evidentemente à disposição expressa no art. $27 \S 4 .^{\circ}$, mesmo com a emenda reclamada pelo autor. Não há privação nem perturbação completa neste gênero de loucura".

Outros autores argumentaram que, embora subsista algum discernimento, a inteligencia não deixa, por isso, de ser alterada em sua totalidade; que se a loucura é diversa em suas manifestações, é una em sua natureza (Culerre). Outros consideram que, se há algum discernimento, é por mera casualidade. $\mathrm{E}$ argumentaram que o animal, como a criança, considerados irresponsáveis, às vêzes temendo as consequências, sabem discernir entre o bem e o mal.

Outros ainda (Lépine, Cajal), admitem lesões parciais das células nervosas, o que leva a supor a coexistência da sanidade e da enfermidade mentais, considerando, assim, a semi-responsabilidade.

O nosso legislador limitou-se a uma determinação geral, não especificando os casos de perturbação completa. Seria dificílimo, senão impossível, denominar e classificar, tendo em vista o gráu de responsabilidade, todos os casos particulares da perturbação dos sentidos e inteligência.

A legislação penal anterior à referida Consolidação adotava a denominação de "loucos de todo o gênero". Mas, - diz Tobias Barreto: " "os loucos de todo o gênero, a soma de todos êles 
é inferior ao total dos que são irresponsáveis em consequência das desordens da economia psíquica; e daí podem resultar, como de fato têm resultado, não poucas injustiças no exercício da penalidade".

Para melhor apreciarmos a intenção do autor da Consolidação, é de mister que recorramos à fonte da disposição de lei em questão, que é o artigo $121 \S 9 .^{\circ}$, do Código da Baviera, que estabeleceu não ser passível de penalidade o ato que fôr resolvido e executado numa "perturbação qualquer dos sentidos ou da inteligência, — não imputável ao agente, - e durante a qual êste não tivesse tido a consciência do dito ato ou de sua criminalidade".

O legislador brasileiro suprimiu a frase - "não imputável ao agente" - , do artigo original, considerando como circunstância agravante, segundo o artigo $39 \S 2 .^{\circ}$, o fato de "ter sido o crime cometido com premeditação". Como atenuante, previu sòmente o caso, no agente, de "embriaguez incompleta, e não procurada como meio de animar à perpetração do mesmo, não sendo acostumado a cometer crimes nêsse estado", conforme o artigo $42 \S 10 .^{\circ}$.

Não eram passíveis de penalidade, segundo o artigo 24 , as ações ou omissões cometidas sem intenção criminosa, ou que não resultassem de negligência, imprudência ou imperícia.

Os elementos essenciais comuns do crime são dois: o elemento moral, subjetivo, constituido pela vontade inteligente e livre do agente; e o elemento material, objetivo, que é o ato externo. Sem vontade inteligente e livre não pode haver dolo. Ora, o legislador não poderia punir aquêle que se achava, no ato de praticar o crime, em estado de completa perturbação dos sentidos e inteligência.

A frase perturbação qualquer, do Código Bávaro, foi substituida por completa perturbação. Sòmente a completa perturbação, pois, torna o indivíduo irresponsável. 0 nosso legislador parece não ter previsto o caso da perturbação incompleta (que é abrangida também pela denominação qualquér, da fonte do dispositivo) durante a qual o agente não tivesse consciên- 
cia do ato ou de sua criminalidade. 0 artigo de lei, por isso, rigorosamente considerado, não abrangia em sí todos os casos de irresponsabilidade por perturbação dos sentidos e inteligência. O mesmo legislador, porém, a julgar pelas suas próprais palavras na expressão completa perturbação, em relação aos casos todos de perturbação, parece ter seguido a mesma ordem de idéias de Cullerre ao se referir á loucura: "qualquer que seja na aparência o círculo restrito em que se move o delírio, a inteligência não deixa de ser perturbada em sua totalidade". Exige que a perturbação exclúa a livre determinação da vontade. Ora, se a perturbação incompleta pode gerar (no entender de vários autores, inclusive o citado Dr. Souza Lima) a exclusão da livre vontade e se êste fato basta para tornar um indivíduo irresponsável, claro é que o legislador, embora exigindo a perturbação completa, previu nessa expressão todos os gráus de intensidade da perturbação, onde não haja livre vontade, excluidos, é bem de ver, os casos especificados em outros dispositivos, pois que nêles são previstos sempre os casos em que existe, pelo menos em parte, a livre determinação da vontade (art. $\left.42, \S 10 .^{\circ}\right)$.

"A irresponsabilidade, - diz o autor do artigo, - ou deriva do estado de inconsciência, ou de qualquer alteração, transitória embora, da psicose, que exclúa a livre determinação da vontade".

0 êrro, pois, foi de palavra. A intenção do autor da Consolidação, porém, foi de considerar irresponsáveis todos aqueles a quem faltasse absolutamente, no ato do crime, a livre determinação da vontade.

Deveria, pois, o autor do Codigo, ter conservado a palavra qualquer, mais certa, por englobar tôdas as perturbações no grau em que possam constituir irresponsabilidade.

0 art. 22 do Código Penal vigente (Decreto-Lei n. ${ }^{\circ} 2848$ de 7 de dezembro de 1940) diz:

"É isento de pena o agente que, por doença mental ou desenvolvimento mental incompleto ou retardado, era, ao tempo da ação ou da omissão, inteiramente incapaz de entender o ca- 
racter criminoso do fato ou de determinar-se de acôrdo com êsse entendimento".

Doença mental, segundo Jorge Severiano, citado por Ribeiro Pontes, é "o desarranjo ou perturbação mental de alguém".

Desenvolvimento mental retardado é a "fraqueza de inteligência, devido à parada da evolução cerebral, consecutiva a causas que agiram antes do nascimento ou a perturbações sobrevindas na primeira idade". A deficiência intelectual varia de intensidade, indo da ausência completa às fronteiras da normalidade, segundo Acilino de Leão.

Não basta, entretanto, a doença mental ou o desenvolvimento mental incompleto ou retardado, para a inimputabilidade, segundo o citado artigo. Faz-se mistèr que tal ocorra durante a ação ou omissão; e ainda que tais estados tornem o agente "inteiramente incapaz de entender o caráter criminoso do fato ou de determinar-se segundo êsse entendimento".

0 parágrafo único do art. 22 estabelece que a pena pode ser facultativamente diminuida, se o agente, ao tempo da ação ou da omissão, não possuía " a plena capacidade de entender o caráter criminoso do fato ou de determinar-se de acôrdo com êsse entendimento".

Não sofrendo o hipnotizado de doença mental ou de desenvolvimento mental retardado, é claro que não pode achar guarida, nem no art. 22 , nem no seu parágrafo único.

Daí, a nosso ver, a superioridade do dispositivo antigo sôbre o atual, pois êste exige, adotando o processo bio-psicológico, a concomitância da doença mental ou do desenvolvimento mental incompleto ou retardado com a incapacidade total ou relativa do entendimento ou da determinação.

A Consolidação considerara, no seu artigo $27 \S 4 .^{\circ}$, como irresponsáveis todos aquêles que, possuidores ou não de doença mental ou de desenvolvimento mental incompleto ou retardado, (excetuados os casos de imbecilidade nativa, 
prevista pelo art. $27 \S 3 .^{\circ}$ ) se achassem, no ato de cometer o crime em estado de completa perturbação dos sentidos ou inteligência, isto é, não possuissem, em última análise, a livre determinação da vontade.

Não eram, assim, considerados criminosos os que fossem impelidos a cometer o crime por violência física irresistivel (art. $\left.27 \S 5 .^{\circ}\right)$.

0 Código vigente, no seu art. 18, não pune aquele que pratica o crime sob coação irresistivel. Não adotando a expressão violência física e sim coação, prevê os casos, tanto de coação física como de coação moral. "A coação - diz Ribeiro Pontes - pòde ser física e pòde ser moral". E a coação moral, segundo Whitaker, citado pelo referido autor, "é a opressão do lívre-arbítrio". Se a coação é resistível, a pena é atenuada, segundo preceitúa o artigo $48, n .^{\circ}$ IV letra c.

Analisadas, em resumo, as disposições referentes á responsabilidade, passamos ao estudo do fenômeno do hipnotismo, para, observando a influência da hipnose sôbre o mecanismo da vontade do agente criminoso, situarmos êste perante o Código Penal Brasileiro.

CONCEITO E HISTÓRICO DO HIPNOTISMO.

A hipnose (do grego, hypnos - (sono) é o conjunto de estados particulares do sistema psíquico, produzidos por manobras artificiais.

Êstes estados produzem no paciente efeitos que, em certos casos, têm a aparência dos efeitos do sono natural. A sua gradação inicia-se, também pelo adormecimento, provocado embora. Daí a gênese da palavra.

Conhecido e aplicado desde a mais remota antiguidade, o hipnotismo passou por uma fase de esquecimento, vítima, também, da falta de interesse científico votado a tôdas as ciências chamadas de "ocultas", perseguidas, na Idade-Média, pelo espírito de religiosidade que então imperava.

Sómente pelos meados do século 19 é que BRAID, observando a propriedade que têm os corpos brilhantes de produzi- 
rem o sono, fundou novos processos de hipnose e dedicou profundos estudos ao fenômeno que, antes, era produzido sem que fossem conhecidas as causas.

Em 1854 o hipnotismo foi estudado por vários sábios, entre os quais Azam, Boca e Gros, que procuraram torná-lo conhecido pelo mundo científico, no que foram auxiliados pelos professores Donato e Hansen, que percorreram a Europa com o intúito de observar as várias modalidades e aplicações da nova ciência. Essas experiências levaram CHARCOT, professor da Escola de Paris, a estudar as causas e efeitos do hipnotismo e a considerar o sono hipnótico como sómente aplicavel aos histéricos; ao mesmo tempo que LIEBEAULT, da Escola de Nancy, estudava a importância da sugestão na provocação do sono (BERNHEIM).

Formadas, assim, duas correntes, - a da Escola de Paris e a da Escola de Nancy, - inúmeros cientístas dedicaramse ao assunto, argumentando a primeira Escola a favor da inaplicabilidade, nos indivíduos sãos, do hipnotismo, sustentando outros que qualquer pessoa é passível de hipnose.

Para êstes, o hipnotizado é considerado um autômato, sem vontade própria; ao passo que aquêles o consideram como possuidor da livre determinação dos seus atos, senhor absoluto da sua vontade, portanto.

\section{DEFINIÇÃO}

Para o Dr. SOUZA LIMA, "o estado de hipnotismo não é precisamente o do sono natural, porque naquêle pode-se conservar o conhecimento do mundo exterior e o sistema muscular não oferece a resolução característica do sono". Pode colocar, entretanto, a pessoa numa condição análoga a mais completa e ainda suspender a ação dos sentidos, produzir anestesia, o que permite tirar todo o meio de defesa contra as tentativas criminosas.

A definição tem a vantagem de diferençar, em traços gerais, os sintomas do sono natural, dos efeitos particulares da hipnose. A sua característica principal, porém, é englobar, nu- 
ma síntese, os diversos períodos do sono hipnótico. 0 autor prevê o caso em que pode haver conhecimento do mundo exterior e o em que póde ser suspensa a ação dos sentidos. Depreendese daí que nem sempre há conhecimento do mundo exterior e nem sempre é suspensa a ação dos sentidos. A definição, pois, implica a possibilidade de todos os estados, isto é, da letargia, catalepsia e sonambulismo, conforme a classificação de CHARCOT, como mais adiante veremos.

A interpretação da palavra sentidos é tida na acepção de consciência espontânea, ou melhor, senso íntimo. A falta de ação dos sentidos, pois, traduz-se pela perda do sentimento do Eu e dos próprios atos, o que torna impossível o lívre arbítrio, acarretando, dessa maneira, perante a Lei, a irresponsabilidade.

Referindo-se ao conhecimento do mundo exterior o autor define os estados hipnóticos em que há perceção visual, auditiva, gustativa e tátil. Existem, nêsses estados, nessas graduações do sono, os sentidos, mas na acepção comum de conjunto de atividades sensoriais dependentes do mesmo órgão receptor. A diferenciação, portanto, é bem evidente, com relação ás acepções física e psicológica da palavra sentidos.

\section{PROCESSOS PRODUTORES}

Convém anotarmos desde já, como processos produtores do sono, os fenômenos da ciência chamada de Magnetismo. Estudado por uns como sendo uma ciência á parte do hipnotismo, considerado por outros como a fonte donde êste deriva, restanos considerá-lo nas suas manifestações.

Os fenômenos, tanto de magnetismo como de hipnotismo, na opinião de muitos autores (BERNHEIN, COURNELLES, D'AVIGNON) se assemelham, levando-os a considerar as palavras como sendo duas denominações diferentes do mesmo fenômeno, como fazendo parte da mesma ciência. BRAID, criador do hipnotismo, considera-os como agentes distintos; mas refere-se ao processo magnético de MESMER, diferençandoo do processo hipnótico, e diferencia apenas o processo de provocação do sono e não as duas palavras. MARIUS DECRESPE 
diz que o hipnotismo é uma parte do magnetismo e sustenta que aquêle era praticado por magnetizadores muito antes de aparecer a denominação de Hipnotismo, criada por BRAID e adotada por CHARCOT.

Assim sendo, embora hoje alguns autores procurem diferençar os nomes, considerando-os como pertencentes a duas ciências distintas, o fato é que, se assim fôr, elas têm muitos pontos de contacto, e os seus fenômenos, perante a Lei, são considerados em relação, tão sòmente, às suas consequências. Indaga-se não da causa, mas do efeito.

0 que interessa ao legislador, ao perito, é saber o gráu de responsabilidade que cabe ao paciente dêsse fenômeno, sem cogitar se êle pertence a esta ou aquela fonte.

A provocação do sono póde ser levada a efeito por inúmeros processos que, no dizer do já citado Dr. SOUZA LIMA, filiam-se aos três grupos de influências seguintes: físicas, psíquicas e sensoriais.

Filiados às influências físicas são os processos em que é aplicado o imã, etc. As influências psíquicas agem, ou na esfera intelectual, ou na esfera afetiva. São êsses processos a sugestão, a ameaça, a insinuação, etc. Filiados ás influências sensoriais são os processos que agem sôbre os sentidos (vista, tacto, etc.)

CHAMBARD inclùi também as influências mecânicas e tóxicas como capazes de produzir o estado de hipnose.

BRAID empregava um objeto brilhante e provocava o sono pelo cansaço do globo ocular. CHARCOT, LUYS E DUMONTPELLIER, a lâmpada de magnésio, a luz elétrica, o espêlho giratório, o tam-tam, etc. BINÉT e FERÉ faziam o paciente aspirar um aroma qualquer. RICHER fazia pressão sôbre as têmporas (zonas hipnógenas). PITRES (de Bordéus) usava a pressão brusca de tais zonas (frontes, lóbulos das orelhas, omoplatas, pulsos, etc. ). Os indús adotam a bola de cristal e provocam o sono pela fixação. LIEBEAULT aplicava a simples sugestão.

O Dr. SANCHES HERRERO, com o seu aparelho hipna 
tizador, experimentando sôbre 726 pacientes, observou os seguintes resultados:

Hipnotizados conforme a Escola de Nancy, com ou sem passes, em menos de 25 minutos ............. 206 Hipnotizados com o aparelho, tardando mais de 2 horas 1 Tardando mais de 1 e meia hora .............. 6 Tardando mais de 1 horas $\ldots \ldots \ldots \ldots \ldots \ldots \ldots . \ldots . \ldots . \ldots . \ldots$ Tardando mais de três quartos de hora .......... 78 Tardando mais de meia hora ............... 111 Tardando menos de meia hora .............. 310 Refratários á experiência $\ldots \ldots \ldots \ldots \ldots \ldots \ldots \ldots$ TOTAL $\quad 726$

Portanto, pela estatística referida, os indivíduos mais refratários á experiência poderão ser adormecidos, variando, apenas, o tempo.

\section{FASES}

Com relação á enumeração das fases do sono hipnótico, divergem as Escolas e os autores.

A Escola de Salpetriére (Paris) reconhece três fases, cuja enumeração às vêzes pode ser alterada:

1a.) - Letargia, que é um sono muito profundo, durante o qual o paciente fica privado dos sentidos (gosto, olfato, tacto, etc.) ;

2a.) - Catalepsia, que é caracterizada pelo enrijecimento dos músculos e tensão do sistema nervoso;

3a.) - Sonambulismo, durante o qual o paciente pude realizar certos atos, de que perde a lembrança, ao despertar.

LIEBEAULT, da Escola de Nancy, considera seis gráus do sono hipnótico:

1) - Sonolência ;

2) - Sono leve;

3) - Sono profundo;

4) - Sono muito profundo;

5) - Sonambulismo leve;

6) - Sonambulismo profundo, caracterizados pelos sinais seguinte: 
1) - sinais variáveis, pêso das pálpebras, torpor, fadiga geral, consciência completa.

2) - pálpebras fechadas; a catalepsia começa a aparecer, porém a conciência e a memória persistem.

3) - o paciente executa contra a sua vontade as ordens recebidas; a sensibilidade é diminuida; a consciência persiste, completa.

4) - a atenção do paciente dirige-se para o agente; ouve só o hipnotizador, mas conserva ainda a consciência.

5) - o paciente de nada se recorda, ao despertar; está sujeito á vontade do hipnotizador, que lhe póde impôr alucinações mais ou menos vivas.

6 - consciência total extinta; o paciente depende absolutamente do hipnotizador, que lhe póde impôr atos a executar no estado de vigília; ausência completa de tôda lembrança (no estado de vigília ( com relação ao que lhe foi sugerido durante o sono).

A Escola de Salpetriére (Paris), admitindo três fases, como citámos acima, oferece, também, os sinais gerais e variáveis dos diferentes estados:

No começo do sono (hipnose leve) o páciente tem os membros frouxos.

Na Letargia própriamente dita (1a. fase) o sono é muito profundo. $O$ paciente, nêste estado, nada sente e nada ou pouco ouve; é incapaz de qualquer movimento espontàneo. A respiração é profunda e regular, podendo, em determinadas pessôas, ser apenas perceptível. As pálpebras estão caídas. A anestesia é completa. Os sentidos estão, outras vêzes, obliterados. Em certos casos o paciente tem consciência do que se está passado (contra uma pessoa nêste estado foi cometido um estupro, cita KRAFFT-EBING).

$\mathrm{Na}$ Catalepsia (2a. fase) os membros se endurecem e conservam as posições que lhes forem dadas. 0 indivíduo é consciente, embora sem espontaneidade intelectual. $O$ sono é mais leve. 0 indivíduo deixa-se manejar, o que permite impôr su- 
gestões. Os olhos pódem ou devem estar abertos, e o olhar possui grande fixidez. Pálpebras fixas. Os membros guardam as suas posições. A característica dêste estado é a imobilidade absoluta. A anestesia cutânea é completa, a vista e o ouvido persistem em parte, sendo pequeno, embora, o campo visual Há automatismo de memória. 0 paciente não conserva a lembrança do que se passou durante êste período de sono, embora guarde as últimas impressões de antes de acordar (MAGNIN, CHARCOT, DURVILLE).

No Sonambulismo, (3a. fase) chamado também sonambulismo lúcido, as pálpebras estão geralmente fechadas. Há completa anestesia cutânia Ausência parcial de automatismo. Aptidão ás contraturas. 0 paciente não conservà a lembrança dêste estado. Agirá como uma pessôa desperta, não tendo consciência, também do meio ambiente. Póde-se-lhe ordenar que faça alguma coisa, não só durante o sono, mas também quando despertar. Esta sugestão será executada dias, mêses e até um ano depois de lhe ter sido imposta. Em tal estado a fôrça muscular aumenta, a memória é surpreendente. 0 sonâmbulo poderá cantar uma música ouvida uma só vez, escrever na obscuridade, lêr de olhos fechados, etc. Diz, porém, o Dr. SOUZA LIMA que nêste estado não há completo automatismo; o paciente tem caráter próprio, aversões e preferências. Chega, por vêzes, até a recursar-se a cumprir uma ordem. A falta de lembrança, também, embora isto aconteça mais raramente, pode não ser completa.

\section{SONAMBULISMO ESPONTÂNEO}

Uma vez que estamos tratando do sonambulismo como sendo uma das fases, conforme a classificação de CHARCOT, do sono provocado, faz-se mister tratar aqui do sonambulismo espontâneo, que é definido por MAX SIMON como sendo um estado particular do sono em que percepções reais e ás vêzes auditivas, olfativas e gustativas, e mais ordinàriamente tácteis, produzem imagens fantásticas visuais, que coincídern exatamente com os objetos que dão origem ás percepções reais, e põem, assim, de alguma fórma, o indivíduo que dorme nas condições de vigília. 
É um sonho, não só de idéias, mas de atos. Caracteriza-se, em traços gerais, pelos mesmos fenômenos do sonambulismo provocado, embora o indivíduo nêste estado possa praticar atos próprios de criminalidade, quando o sonho a isso o obriga; ou atos de outrem, quando, nêste estado, são sugestionados (impressões auditivas), muito principalmente quando os sonhos que o preocupam estão em harmonia com as impressões recebidas. A doutrina corrente é a da irresponsabilidade dos sonâmbulos, quando êstes não conceberam, em estado de vigília, o ato que praticam durante o sono.

Os que levam a intenção para consumar o delito no estado sonambúlico ,aquêles que se descuidaram sabendo-se passíveis dêste fenômeno, são considerados como culpados por vários autores. E culpados, ou porque projetaram, premeditaram, ou porque negligenciaram.

A doutrina geral, entretanto, considera os que intencionaram como irresponsáveis, porque a intenção deve ser considerada, em ecrtos casos, e na maioria dêles, como méra casualidade; a negligência, se vier a ser provada, poderá contudo levar o sonâmbulo á incriminação.

\section{SUGESTÃO}

A influência da sugestão é um fator importantíssimo, como vimos. $O$ indivíduo sugestionado, em certos casos, levará a efeito um ato, esquecendo-se da pessôa que ordenou o gesto. A vontade do hipnotizado, em vários casos não é própria. Êle age como um autômato, segundo a Escola de Nancy. Não é considerado, porém, como um autômato, embora seja considerado anormal, pela Escola de Paris (Charcot). A sugestão, além disso, póde ser levada a efeito mesmo á distância, no dizer de muitos. Para isso emprega-se a transmissão do pensamento, o telefone, as cartas, etc.

Excluídos os casos de sonambulismo espontâneo, em que o próprio sonho pode levar o indivíduo á perpetração de um delito, e dos impulsos que poderão advir do estado de hipnotismo, sómente a sugestão será capaz de levar um paciente, dêste estado á tentativa ou consumação de um crime. Autores há, 
entretanto, que consideram a sugestão como relativa, considerada em relação aos que a recebem. Entre êstes cita-se VOIGT, que diz o seguinte: "A maioria das vêzes um bom médium (paciente) executará ordens disparatadas, como mudar de lugar uma cadeira, ver alguém presente com estranho disfarce ou portar-se como se êste houvesse desaparecido. Um sugestionador impulsivo e sem escrúpulos não logrará violar uma mulher se não existir na médium uma tendência para entregar-se. Mas se existem sinais dessa tendência, será possível avivar os impulsos eróticos sufocados e vencer as resistência que se opôem á satisfação.

A sugestão, na opinião do citado autor, não é, pois, absoluta. Ela exagera a tendência para o mal, quando esta tendência existe, sufocada embora. A sugestão, porém, será repelida uma vez que não esteja em harmonia com a consciência do hipnotizado.

É esta, também, a opinião de GAROFALO. Para êste, o crime não é "o efeito direto e imediato das circunstâncias externas; está sempre no indivíduo e é a revelação de uma natureza degenerada, quaisquer que sejam as causas, antigas ou recentes, dessa degeneração. Nêste sentido, o delinquente fortúito não existe".

\section{OBSERVAÇõES}

$\mathrm{Na}$ opinião de certos autores, para agir de maneira eficaz na realização de uma sugestão, é necessário conseguir do espírito do paciente o desejo de realizar esta sugestão. 0 cérebro humano, no seu entender, compõe-se de duas partes: uma que analisa as impressões recebidas, outra que é destinada a executar as ordens dadas pela parte superior, quer esta parte pertença á própria pessôa, quer pertença a outrem.

No estado de hipnose, a parte superior está adormecida e a parte inferior aceita as ordens que lhe são determinadas pela parte superior de outra pessôa, contanto que estas sugestões não sejam contrárias á consciência do paciente. 0 hipnotizado, portanto, só admitirá as sugestões que se não oponham á sua consciência (senso íntimo). 
Em esperiências realizadas pelo Dr. LIEGEOIS observou-se o seguinte: foi adormecido um homem reconhecido como honesto, a quem o citado Dr. sugeriu que pegasse um revólver, fôsse a tal lugar, abrisse uma gaveta e tirasse dalí todo o dinheiro. 0 indivíduo executou tôdas as ordens, enganando-se sómente num fato: pegou uma pistola, em vez de pegar um revolver.

Outros autores afirmam que a sugestionabilidade do paciente em nada inflúi para a produção do sono. Negam a influência da imaginação do paciente e argumentam que se póde obter o efeito da hipnose sôbre uma criança e mesmo sôbre um animal, sem que êles em tal consintam. (H. DURVILLE. "Teorias e processos do Magnetismo").

Do expôsto, conclúi-se que, conforme certos autores, não é indispensável o estado sensitivo, a imaginação do paciente. E se, para uns, o "hipnotizador nada é, o paciente é tudo" (LUYS) e "todos os fenômenos têm fonte única e comum no sistema nervoso do paciente (BRAID), para outros a influência da imaginação do sensitivo é nula (DURVILLE).

Pelas experiências citadas, continúa a dúvida, no que diz respeito ao automatismo ou não do paciente. Para certos estudiosos do assunto póde haver resistência ás sugestões no estado hipnótico, desde que a ordem não esteja de acôrdo com o caráter do hipnotizado (HEYER). Para LIEGEOIS o paciente é um autômato.

\section{O PROBLEMA PENAL}

Perante a legislação brasileira, desde que se prove a exclusão, no hipnotizado, da livre determinação da vontade, a responsabilidade deixa de existir. Sendo adotado o critério da Escola de Nancy, o paciente do sono provocado ou de suas consequencias é um autômato, não possuindo vontade livre e, portanto, liberdade de discernir entre o bem e o mal.

A jurisprudência sôbre a matéria é raríssima. Tratadistas de nomeada, entre os quais o Dr. SOUZA LIMA, estudaram a questão. Repetindo EBING, diz o citado autor, referin- 
do-se aos casos de loucura transitória enfeixados no artigo 27 $\S 4 .^{\circ}$ da antiga Consolidação da Leis Penais da República: "á intensidade dêsse estado mórbido corresponde a alteração da consciência, mesmo a sua supressão e a lacuna correspondente da memória. A falta de memória, completa ou não, a sua insuficiência, que implicam a alteração ou supressão da consciência, levam ao conhecimento do gráu e das modalidades dessa perturbação". A amnésia, portanto, prova a inconsciência e, conseguintemente, a irresponsabilidade.

O hipnotizado esquece; ou espontâneamente ou por sugestão. Durante o estado sonambúlico, porém, êle tem consciência dos seus atos, segundo a Escola de Paris. A inteligência e a memória são perfeitas (SOUZA LIMA). Póde, portanto, racionar e não cumprir o ato criminoso que se lhe ordenar. Discerne, assim, entre o bem e o mal. À medida que o sono atravessa as várias fases, os sentidos tornam-se superexcitados. Mas não há espontaneidade intelectual, no dizer da Escola contrária. $\mathrm{O}$ indivíduo, mesmo conservando a consciência do seu $\mathrm{Eu}$, muitas vêzes possuindo um caráter contrário ao ato, executa a ordem criminosa, sem fôrças para impedir o seu próprio gesto.

Em estado de vigília executa também um ato criminoso, com consciência, com os sentidos físicos apurados, com a imaginação exaltada, com conhecimento do mundo exterior, mas sem vontade, sem fôrças para resistir á sugestão que recebeu durante o estado de hipnose e olvidou ao acordar, julgando, como muitas vêzes foi observado, estar agindo de motupróprio, estranhando, muito embora, o seu gesto.

A psicologia explica, - diz GALDINO DE SIQUEIRA que a memória descende da atenção. "No hipnotizado a aten ção é perfeita desde que o agente sugira esta atenção. Uma vez percebido um fato, êste é rememorado, ou melhor: só o fato a que se prestou atenção é que póde ser rememorado. A sugestão póde mandar esquecer, mas o esquecimento, então só poderá dar-se no estado de vigília. A memória retornará, desde que o paciente seja novamente adormecido. E se êle percebeu, por hipótese, no sono, sómente poderá recordar no sono, em regra geral. 
0 agente do delito, pois, não esquece o que está fazendo; não esquece que agiu e chega mesmo a condenar-se, mais tarde, pelo ato que praticou. Olvida, apenas, o que aconteceu num estado psicológico diferente. Se está em vigília, esquece o sono: e vicce versa.

O esquecimento, por conseguinte, não é concomitante com $o$ ato do delito. $\mathrm{E}$ se, no estado de sono provocado, o paciente recorda-se, é porque teve consciência, no sono anterior. Sem o que, não poderia recordar.

A questão, assim, resume-se no libertas consilíi. Será a própria vontade do indivíduo que agiu? Pôde êle discernir entre o bem e o mal? 0 seu ato foi consciente, porque êle soube 0 que estava fazendo e póde recordar.

Não foi sua, porém, a intenção; o animus agendi não foi seu, segundo a Escola de Nacy. Em resumo: houve a liberdade de fazer. Não houve, entretanto, a liberdade de querer.

Em Medicina Legal, - diz GALDINO de SIQUEIRA inconsciência é o estado em que o indivíduo não é senhor da razão e dos sentidos, mas continúa a agir e a viver, relacionado com o mundo externo por intermédio das alucinações, de concepções delirantes e por visões de sonho".

Perante 0 artigo $27 \S 4 .^{\circ}$ da antiga Consolidação das Leis Penais da República, o hipnotizado tinha, pois, lugar? A perturbação dos sentidos, isto é, a inconscoiência, não existe senão no estado de vigília. A inteligência, - elaboradora dos dados fornecidos pela consciência espontânea, pelo senso íntimo, tornando possiveis o juizo ético e o raciocínio das consciências refletidass, o discernimento entre o bem e o mal, estará, é claro, perturbada porque não poderá elaborar o juizo ético, o discernimento, uma vez que parece, em consequência do estado de inconsciência, o lívre arbítrio. Além disso, a perturbação é completa, porque decorre da amnésia e esta é completa. Mas essa perturbação completa dos sentidos ou da inteligência será concomitante da ação delituosa? 
No estado de vigília o paciente não está perturbado completamente dos sentidos, uma vez que apreende, e tem conhecimento do seu estado de alma particular; possúi atenção e memória relativas a todos os seus atos desde que despertou. A inteligência, aqui considerada como faculdade de discernir entre o bem e o mal, de elaborar o juizo ético, não existe, segundo a Escola de Nancy. A perturbação dos sentidos não é, pois, completa; ao passo que não existe a liberdade de discernir entre o bem e o mal.

E não existindo a liberdade de querer, não existe a intenção criminosa. Não havendo o animus agendi poderia ser considerado como responsável o indivíduo que não preenchia os requisitos do dispositivo que exige, para a caracterização da irresponsabilidade, a perturbação completa no ato de cometer o crime?

Daí a necessidade do estudo personalíssimo da pessoa que age sob a influência do hipnotismo, pois só assim será possível saber-se do gráu de responsabilidade. Uma vez excluida a livre determinação da vontade, não há responsabilidade, não sendo necessária, segundo o autor da referida Consolidação, a perturbação completa dos sentidos ou da inteligência.

Póde, ainda, haver culpa; ou coação irresistível, que, como vimos, é física ou moral, segundo o artigo 18 do Código Penal vigente.

Problema interessante, o do hipnotismo perante o Código Penal. E que só poderá ser satisfatòriamente resolvido, e com justiça, com o estudo do indivíduo que agiu sob influência hipnótica, conhecidos os vários gráus dessa influência, observando-se se, no ato do crime, possuia, ou não, o seu autor, a livre determinação da vontade, atributo básico para a caracterizaçã̃o da responsabilidade penal. 